Dubes, G. R. \& Chapin, M. (1958). J. gen. Microbiol. 18, 320-329

\title{
Poliovirus Mutants with Altered Responses to Gystine
}

\author{
By G. R. DUBES AND MARGARET CHAPIN \\ Department of Pediatrics and the Hixon Memorial Laboratory. The University \\ of Kansas School of Medicine, Kansas City, Kansas, U.S.A.
}

SUMMARY: Three strains of poliovirus (Akron, antigenic type 1; Brooks, type 2; Mabie, type 3), which require exogenously supplied cystine (or a cystine-substitute) for optimal cytopathogenic action on monkey kidney tissue cultures, were serially passaged ten times in cystine-deficient monkey kidney tissue cultures in tubes. From various passage levels in this system were isolated three mutants of Akron, four of Brooks and two of Mabie. These nine mutants are designated the cystine-response mutants and are distinguishable from their ancestral viruses used to initiate the passage series by being relatively cystine-non-requiring. Two criteria suffice to distinguish the mutants of any strain from each other: (1) the degree of loss of requirement for cystine, and (2) the degree of inhibition by relatively high concentrations of cystine. The compositions of the virus populations in most of the passage levels were determined, and from these determinations the patterns of emergence of the mutant viruses were delineated.

Several poliovirus mutants which are classifiable on mammalian cells in vitro have been obtained. Dulbecco \& Vogt (1955) reported an $r$ (rapid) mutant of the Brunhilde strain (antigenic type 1 ). This $r$ mutant was originally characterized by its relatively large plaques on monkey kidney tissue cultures in a medium containing embryo extract but has since been renamed the $d$ (delayed) mutant because it can be more readily classified on the basis of its characteristic delay on monkey kidney cells maintained in a relatively acid medium (Vogt, Dulbecco \& Wenner, 1957). Several independent occurrences of this type of mutant in other strains of poliovirus have been reported (Sabin, 1956; Vogt et al. 1957). A heat-resistant variant of the MEF 1 (type 2) strain of poliovirus was obtained by Stanley, Dorman, Ponsford \& Larkin (1956) and heat-resistant mutants $\left(t_{1}\right.$ and $\left.t_{1} t_{2}\right)$ of the Brunhilde strain were reported by Dulbecco (1956). Slow Mahoney (Dubes, 1956 a) is an $m$ (minute) mutant of the Mahoney strain (type 1) and can be readily classified on the basis of its tiny plaques on monkey kidney tissue cultures. Cold-adapted genetic variants (Dubes \& Chapin, 1956) of strains Akron (type 1), Brooks (type 2) and Mabie (type 3) are characterized by their relatively high rate of propagation on monkey kidney tissue cultures maintained at $30^{\circ}$. Genetic variants further adapted to the HeLa cell system have also been obtained (Dubes \& Wenner, 1957). Recently, Takemori et al. (1957) reported Mahoney and MEF 1 mutants which are resistant to the substance(s) which can be found in normal adult bovine sera and which inhibits the 'wild-type' Mahoney and MEF 1 viruses.

The demonstration that three strains (Akron, Brooks, Mabie) of poliovirus require exogenously supplied cystine or a cystine-substitute for optimal cytopathogenic action on monkey kidney tissue cultures (Dubes, 1956b) and the 
general success of the technique of passage under conditions favouring the selection of mutants suggested the possibility of obtaining cystine-nonrequiring mutants through passage of polioviruses on cystine-deficient monkey kidney tissue cultures. The emergence and characterization of relatively cystine-non-requiring mutants obtained through such selective passages are the subject of this paper. Part of this work has been reported in abstract form (Dubes \& Chapin, 1957). The relative virulence in monkeys of some of these mutants has been studied and will be reported elsewhere (Dubes $\&$ Wenner, 1957), with a brief summary of their characterization on cells in vitro.

\section{METHODS}

Poliovirus strains. Akron purified pool no. 1 (PP1), Brooks PP1 and Mabie PP la, all of which are cystine-requiring strains, were chosen for passage and study. The formation of these purified pools has already been described (Dubes, $1956 a)$.

Monkey kidney tissue cultures. Kidney cells from rhesus (Macaca mulatta) or cynomolgus $(\boldsymbol{M}$. irus) monkeys were dispersed with trypsin and grown on medium $D$ (Younger, 1954) for 6 days at $35-37^{\circ}$ in $150 \times 16 \mathrm{~mm}$. test tubes, $60 \mathrm{~mm}$. diameter Petri plates, or $200 \mathrm{ml}$. screw-cap serum bottles with square cross-section. In a few experiments the growth medium of Melnick (1955) was used in place of medium D. After this growth period the cultures were washed three times with cold phosphate-buffered saline (PBS) (Dulbecco \& Vogt, 1954), the tube cultures each time with $2 \cdot 0 \mathrm{ml}$., the plate cultures each time with $4.25 \mathrm{ml}$., and the bottle cultures each time with $10 \mathrm{ml}$. After virus inoculation, the cultures were maintained at $35-37^{\circ}$ on $0.90,6.0$ and $10 \mathrm{ml}$. of a maintenance medium for tubes, plates and bottles, respectively. The maintenance overlay for the Petri plates contained $0.90 \%(\mathrm{w} / \mathrm{v})$ washed agar. The maintenance media used were based on Eagle's maintenance medium $\left(\mathrm{E}_{\mathrm{m}}\right)$ (Dubes, 1956b). Medium $\mathbf{E}_{\mathrm{m}}$ and an altered $\mathbf{E}_{\mathrm{m}}\left(\mathrm{AE}_{\mathrm{m}}\right)$, which was developed by Miss Joanne Rush for use in this laboratory, were used without cystine, or with cystine at concentrations within the range of 0.050-1.0 mM. Medium $\mathbf{A E}_{\mathrm{m}}$ differs from $\mathbf{E}_{\mathrm{m}}$ in that it contains Hanks's balanced salt solution (Hanks \& Wallace, 1949) in place of the salt solution used by Eagle (1955); the concentration of sodium bicarbonate is, however, kept at $20 \mathrm{~mm}$. All maintenance media were adjusted to a $\mathrm{pH}$ value between $6 \cdot 4$ and $6 \cdot 8$ for use in tube and bottle cultures, and to $\mathrm{pH} 7 \cdot 0$ for use in the plaque method on Petri plates. Tubes and bottles were sealed. Cultures in tubes were rolled after inoculation. Petri plate cultures were kept in a humidified incubator which was continuously flushed with $3 \%(\mathrm{v} / \mathrm{v})$ carbon dioxide and $97 \%(\mathrm{v} / \mathrm{v})$ air (Dulbecco \& Vogt, 1954) and were stained with neutral red 4-8 hr. before examination (Dubes, $1956 a$ ). In general, the plaque method used was adapted from the original method of Dulbecco \& Vogt (1954).

Inoculations with viruses. Viruses were diluted in PBS; $0 \cdot 10,0.30$ and $\mathbf{1 . 0} \mathrm{ml}$. of each appropriate dilution were inoculated into tube, plate and bottle cultures, respectively. 
Storage of viruses. All virus stocks were stored in rubber-stoppered ampoules in a dry-ice box.

Passages of viruses on kidney cultures unsupplied with cystine. Samples from Akron PP 1, Brooks PP 1 and Mabie PP la were passaged ten times serially in tissue cultures maintained on $\mathrm{E}_{\mathrm{a}}$ without cystine. The inoculum for each passage was virus usually at $10^{-2}$ concentration, equivalent to $10^{3}$ to $10^{5}$ plaque-producing particles inoculated per tube. Between two and six tubes were used for each passage of each strain. Tube cultures were harvested when they exhibited $90-100 \%$ cytopathogenic degeneration. The tenth-passage virus of each strain was then passaged three times serially by the plaque method on cells maintained on $\mathbf{E}_{\mathrm{m}}$ minus cystine. Each third serial plaque isolate was then inoculated for pool formation into several bottle cultures on the same medium. The pools so obtained were designated Akron PP5, Brooks PP5 and Mabie PP 5. The virulence in monkeys of these three viruses has been studied (Dubes \& Wenner, 1957).

Genetic purification and pool formation with the other viruses emerging during the passages. From various of the tube-passage levels polioviruses differing from both the PP1's and PP 5's were isolated. Purifications and pool formations with these viruses were performed in the same manner as with the PP5's, except that in some cases the purifications by the plaque method were performed on cystine-supplied cells so that plaques of desired appearance might be selected for isolation.

Typing of viruses. The antigenic type of each virus pool was confirmed in neutralization experiments against the three specific poliovirus antisera formed in monkeys (Wenner, Miller, Kamitsuka \& Wilson, 1954) and against normal monkey serum as a control.

$S y m b o l s$ for the mutant viruses. To avoid unwieldy descriptions when referring to the various mutants the designations and symbols defined in Table 1 have been used. These symbols do not imply that the phenotypic differences between the various mutants are due to single genetic differences. Akron PP1, Brooks PP1 and Mabie PP1a, the cystine-requiring viruses from which the mutants were derived, are referred to as wild-type $\left(+{ }^{c r}\right)$ viruses in regard to cystine response. Akron PP5 and Mabie PP5 are $c^{i}$ viruses, whereas Brooks PP 5 is $c r$ virus. The criterion of degree of inhibition by cystine (Table 1 ) is based on the 'turbidity' of plaques produced on cells supplied with a relatively high concentration $(0 \cdot 20-1 \cdot 0 \mathrm{~mm})$ of L-cystine. 'Turbid' plaques are plaques which contain a relatively large fraction of neutral red-stainable cells.

Environmental factors affecting the cystine response. The manifestion of a requirement for cystine by the cystine-requiring polioviruses can be modified by varying the temperature during viral action or by establishing the kidney cultures on a different growth medium. For these viruses a lowering of the temperature from $37^{\circ}$ increases the relative plating efficiency on cells not supplied with cystine. Substituting the growth medium of Melnick (1955) for medium $\mathrm{D}$ has a similar effect. These modifications may operate through altering the size of the intracellular pool of cystine or 'cystine-activity', the 
influence of the composition of the growth medium being on the size of this pool at the time of inoculation and the influence of temperature being on the rate of metabolic change of this pool after inoculation.

Table 1. Designations and symbols for wild-type and cystine-response (cr) mutant polioviruses

$++=$ clear requirement for, or strong inhibition by, cystine. $+=$ slight requirement for, or slight inhibition by, cystine. $0=$ no demonstrated requirement for, or no demonstrated inhibition by, cystine.

$\begin{array}{lccc}\quad & \overbrace{\text { Requirement }}^{\text {Virus designation }} & \begin{array}{c}\text { Virus } \\ \text { symbol }\end{array} & \begin{array}{c}\text { Inhibition } \\ \text { by }\end{array} \\ \text { Wild-type } & +{ }^{c r} & ++ & 0 \\ \text { Cystine-response-partial } & c r^{p} & + & 0 \\ \text { Cystine-response } & c r & 0 & 0 \\ \text { Cystine-response-slightly inhibited } & c r^{8 i} & 0 & + \\ \text { Cystine-response-inhibited } & c r^{i} & 0 & ++\end{array}$

\section{RESULTS}

Akron cr mutants

Early tests demonstrated clearly that Akron PP5 $\left(c r^{i}\right)$ differs from its progenitor PPI $\left(+{ }^{c r}\right)$ virus in response to cystine. The Akron $c r^{i}$ mutant shows no requirement for exogenously supplied cystine under the conditions employed: moreover, it produces 'turbid' plaques on monkey kidney cells under an agar layer which contains a relatively high concentration $(0.20$ to $1.0 \mathrm{~mm})$ of L-cystine.

Platings of the various tube-passage virus populations leading to the isolation of the $c r^{i}$ mutant were made on cells unsupplied and on cells supplied with cystine. In these experiments the $+{ }^{c r}$ and $c r^{i}$ viruses were similarly plated so that comparisons could be made with the viruses at different passage levels using three criteria: (1) plating efficiency without cystine relative to efficiency with cystine; (2) plaque size with and without cystine; and (3) plaque appearance with and without cystine. The results obtained from these comparisons indicated that two other viruses, the $c r$ and $c r^{s i}$ mutants, which are different from each other and from both the $+^{c r}$ and the $c r^{i}$ viruses, were also obtained in the series of passages on cystine-deficient cells in tubes. Purified pools of the $c r$ and $c r^{s i}$ mutants were prepared from isolates obtained from tubepassage levels 2 and 5 , respectively. The $c r$ mutant may be characterized as cystine-non-requiring and cystine-uninhibited and the $c r^{s i}$ mutant as cystinenon-requiring and slightly cystine-inhibited. The data from a typical experiment showing the differentiation of these three Akron cystine-response mutants and of wild-type Akron are presented in Table 2. In this experiment the cells had been grown on medium $D$ and plaques developed for 4.0 days in a continuously flushed incubator at $36 \cdot 6^{\circ}$. The difference between the $+^{c r}$ and $c r^{i}$ viruses is illustrated by $\mathrm{Pl}$. 1 , fig. 1 .

The proportions of the $+^{c r}, c r, c r^{s i}$ and $c r^{i}$ Akron polioviruses in the various tube-passage levels were estimated by using the three criteria mentioned above 
(relative plating efficiency, plaque size and plaque appearance) and by characterization of the viruses in some plaque isolates from some passage levels by the same criteria. Such classifications of the viruses in the passage levels gave the pattern of emergence of these three Akron mutants presented in Fig. 1.

Table 2. The differentiating characteristics of the wild-type and cystine-response mutant Akron, Brooks and Mabie polioviruses on monkey kidney cells in vitro

Differentiating characteristics

\begin{tabular}{|c|c|c|c|c|c|}
\hline \multirow[b]{2}{*}{ Poliovirus } & \multirow[b]{2}{*}{ RPE (\%) } & \multicolumn{2}{|c|}{$\begin{array}{c}\text { Mean plaque } \\
\text { diameter (mm.) }\end{array}$} & \multicolumn{2}{|c|}{ Plaque appearance } \\
\hline & & $\begin{array}{c}\text { With } \\
\text { cystine* }\end{array}$ & $\begin{array}{l}\text { Without } \\
\text { cystine } \dagger\end{array}$ & $\begin{array}{c}\text { With } \\
\text { cystine* }\end{array}$ & $\begin{array}{l}\text { Without } \\
\text { cystine† }\end{array}$ \\
\hline Akron $+c r$ & $0 \cdot 14$ & $3 \cdot 7$ & $1 \cdot 6$ & Clear & Clear \\
\hline Akron $c r$ & 71 & $4 \cdot 4$ & $4 \cdot 3$ & Clear & Clear \\
\hline Akron $c r^{s i}$ & 190 & $2 \cdot 5$ & $6 \cdot 0$ & $\begin{array}{c}\text { Slightly } \\
\text { turbid }\end{array}$ & Clear \\
\hline Akron $c r^{i}$ & 130 & 3.9 & $5 \cdot 6$ & Turbid & Clear \\
\hline Brooks $+{ }^{c r}$ & 0.069 & $7 \cdot 1$ & $2 \cdot 9$ & Clear & Clear \\
\hline Brooks $\operatorname{cr}{ }^{p}$ & 57 & $7 \cdot 8$ & $4 \cdot 0$ & Clear & Clear \\
\hline Brooks $c r^{i}$ & 120 & $5 \cdot 4$ & $3 \cdot 4$ & Turbid & $\begin{array}{l}\text { Slightly } \\
\text { turbid }\end{array}$ \\
\hline Brooks $c r^{s i}$ & 110 & $5 \cdot 7$ & $5 \cdot 9$ & $\begin{array}{r}\text { Slightly } \\
\text { turbid }\end{array}$ & Clear \\
\hline Brooks $c r$ & 200 & $6 \cdot 4$ & $6 \cdot 0$ & Clear & Clear \\
\hline Mabie $+{ }^{c r}$ & $2 \cdot 1$ & $7 \cdot 0$ & $1 \cdot 2$ & Clear & Clear \\
\hline Mabie $c r^{8 i}$ & 120 & $4 \cdot 8$ & $4 \cdot 5$ & $\begin{array}{l}\text { Slightly } \\
\text { turbid }\end{array}$ & Clear \\
\hline Mabie $c r^{i}$ & 260 & $3 \cdot 5$ & $4 \cdot 8$ & Turbid & Clear \\
\hline
\end{tabular}

* Medium AEm with L-cystine at 1.0 mM for Akron and Brooks and at 0.50 mM for Mabie.

$\uparrow$ Medium AEm without cystine. RPE (relative plating efficiency) is the plating efficiency without cystine relative to the efficiency with cystine. The data are from 3 experiments, 1 for each strain. See Table 1 for an explanation of the symbols for the viruses.

\section{Brooks cr mutants}

The general procedure followed with Akron was also used with Brooks. The virus in Brooks PP 5 produces clear plaques in the presence of high concentrations of cystine, in contrast to the turbid plaques produced by Akron PP 5, and is thus designated $c r$. This $c r$ mutant may be differentiated from the original Brooks $+{ }^{c r}$ virus on the basis of its lack of requirement for exogenously supplied cystine. Comparisons of the tube-passage virus populations with the ${ }^{+c r}$ and $c r$ viruses indicated that three other mutants, the $c r^{p}, c r^{i}$ and $c r^{s i}$ mutants, also emerged during the series of tube passages. Purified pools of the $c r^{p}, c r^{i}$ and $c r^{s i}$ mutants were prepared from isolates obtained from tubepassage levels 1,2 and 4, respectively. In Table 2 data from a typical experiment showing the distinguishing characteristics of these three mutants and the $+{ }^{c r}$ and $c r$ viruses are presented. In this experiment the cells had been grown on medium $D$ and the plaques developed for 4.0 days in a continuously

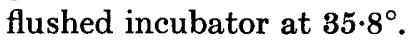


The pattern of emergence of these four Brooks cystine-response mutants was determined in the same way as was the pattern for Akron and is shown in Fig. 1.

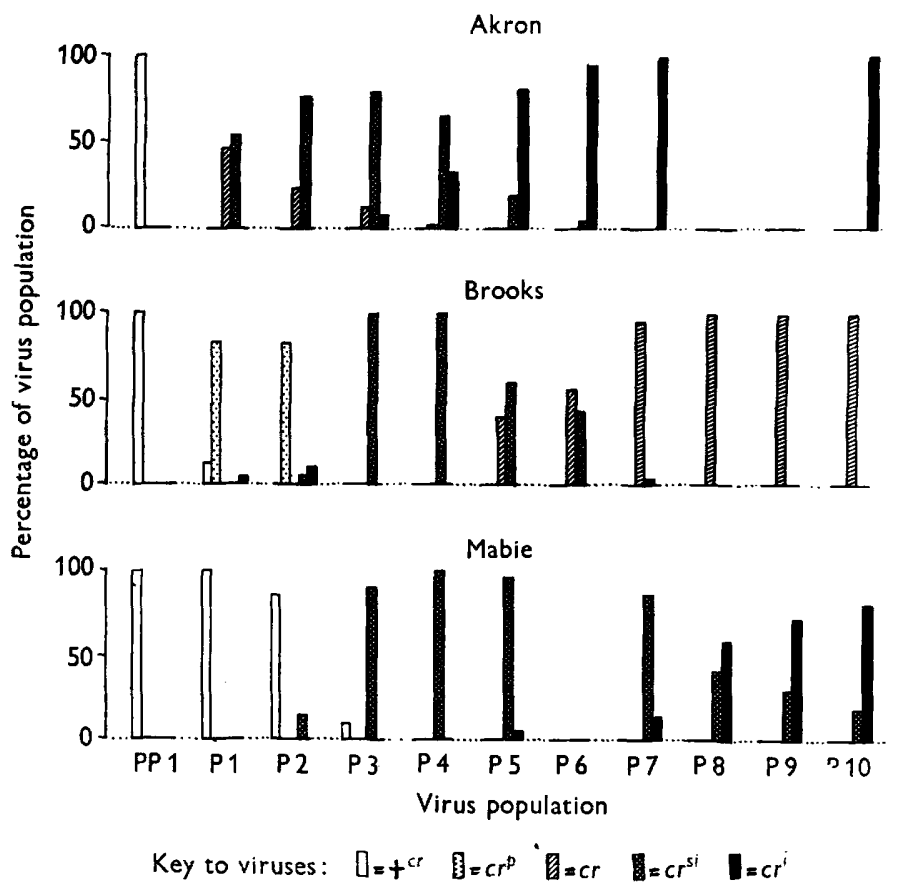

Fig. 1. The patterns of emergence of the cystine-response mutants. PP1 (PP 1a for Mabie) is the starting pool of $+^{c r}$ virus. Designations P1 through P10 indicate the serial numbers of rapid consecutive passages in tube culture. See Table 1 for an explanation of the symbols for the viruses. Data for P8 and P9 of Akron and for P6 of Mabie were not obtained.

\section{Mabie cr mutants}

Mabie PP 5 contains a virus which has a cystine-response similar to that of the Akron $c r^{i}$ mutant and is thus called the Mabie $c r^{i}$ mutant. Another Mabie mutant, the $c r^{s i}$ mutant, also emerged during the tube passages. A purified pool of this mutant was prepared from an isolate from tube-passage level 5 . Data which show the differentiation of the Mabie $c r^{s i}, c r^{i}$ and $+^{c r}$ viruses are given in Table 2. These data were taken from a typical experiment in which the cells had grown on medium $\mathrm{D}$ and the plaques developed for 4.0 days in a continuously flushed incubator at $36 \cdot 7^{\circ}$. A visual comparison of the $+{ }^{c r}$ and $c r^{i}$ viruses is afforded by $\mathrm{Pl} .1$, fig. 2.

The pattern of emergence of these two Mabie cystine-response mutants was determined and is shown in Fig. 1.

Tests of progeny viruses in plaques formed by $+{ }^{\mathrm{cr}}$ viruses on cells not supplied with cystine

Since viruses with altered responses to cystine appeared so very early in the passage series (Fig. 1) experiments were done to see if a single-plaque passage 
of $a+c r$ virus on cystine-deficient cells would give a virus with an altered cystine-response. Nine, 7 and 3 plaques formed by Akron, Brooks and Mabie ${ }^{c r}$ viruses, respectively, on cystine-deficient cells were isolated and the cystine-responses of the progeny viruses therein were determined. Three of the Akron plaque isolates were characterized in tests performed in tube cultures, a method previously described (Dubes, 1956 b). By these tests the three isolates were not unlike their Akron ${ }^{c}{ }^{c r}$ parent. The other 6 Akron isolates were studied more precisely by the plaque method; one was found to be similar to the Akron $c r$ virus and the other 5 were found to be intermediate between $+{ }^{c r}$ and $c r$. Two of the latter group of 5 isolates were further resolved by characterization of plaque subisolates. From one of these a virus of phenotype intermediate between $+{ }^{c r}$ and $c r$ and a virus somewhat similar to but probably different from $\mathrm{cr}^{s i}$ were isolated. From the other isolate the two subisolates tested proved to be $+{ }^{c r}$. Three of the 7 Brooks isolates were studied in tests in tube cultures and not found to be different from Brooks $+{ }^{c r}$ virus. The other 4 Brooks isolates were studied by the plaque method; 2 were found to be like the Brooks $c r^{p}$ virus and 2 were found to be intermediate between the $+^{c r}$ and $c r^{p}$ viruses. From one of these 'intermediate' isolates 5 subisolates were obtained. Three of these 5 subisolates proved to be like the original 'intermediate' isolate, one was found to be similar to the Brooks $c r^{i}$ virus, and one was $+{ }^{e r}$ virus. The three Mabie isolates were tested in tube cultures and not found to differ from their progenitor virus, Mabie $+{ }^{c r}$. No tests of Mabie isolates by the plaque method were made since the results of these tests in tube cultures and the finding that tube-passage level 1 contained $+^{{ }^{c r}}$ virus (Fig. 1) show that cystine-response mutants of Mabie do not necessarily appear after propagation of Mabie $+{ }^{c r}$ virus on cystine-deficient cells.

Thus relatively cystine-non-requiring viruses of strains Akron and Brooks may be obtained by the isolation of plaques formed after the inoculation of the ${ }^{+c r}$ viruses on to cystine-deficient cells. The data also indicate that some of the progeny viruses in these plaques have an unaltered cystine-response.

\section{Tests of progeny viruses in plaques formed by the Akron $\mathrm{cr}^{\mathrm{i}}$, Brooks $\mathrm{cr}$ and Mabie cr $^{i}$ viruses (PP5's) on cystine-supplied cells}

Plaques formed by Akron $c r^{i}$, Brooks $c r$ and Mabie $c r^{i}$ viruses on cystinesupplied cells were examined for the presence of viruses with cystine-responses different from those of their parents. Such viruses might possibly arise from genetic reversions or simply from the fact that they were synthesized in cystine-supplied cells (cf. Luria, 1953). Seven isolates from typical Akron cr $^{i}$ plaques were tested and found to contain $c r^{i}$ virus. An isolation was also made from an atypical Akron $c r^{i}$ plaque. This plaque was atypical in that it contained a relatively clear sector, i.e. a region in which a relatively low fraction of the cells had concentrated the neutral red. Such atypical sectored plaques are not infrequently found when Akron $\mathrm{cr}^{i}$ virus is plated on cells supplied with cystine at $0 \cdot 20-1 \cdot 0 \mathrm{~mm}$. From the relatively clear sector of this plaque was isolated a virus unlike $c r^{i}$ but somewhat similar to $+^{c r}$. It differed, however, from $+^{c r}$ in producing slightly turbid instead of clear plaques on 
cystine-supplied cells and possibly also in having an even lower relative plating efficiency on cells not supplied with cystine. Eight and 6 typical plaques from Brooks $c r$ and Mabie $c r^{i}$, respectively, were isolated. Each contained virus like its parent.

These findings show that the progeny viruses in typical plaques formed by the cystine-non-requiring Akron $c r^{i}$, Brooks $c r$ and Mabie $c r^{i}$ viruses on cystine-supplied cells are like their parental viruses. Thus the nature of these progeny viruses is not determined by the amount of cystine supplied to the cells in which they were synthesized. The cystine-requiring virus which was obtained from the sector of a sectored plaque formed by Akron $c r^{i}$ virus very probably arose through genetic reversion from $c r^{i}$ during the propagation of the $c r^{i}$ virus on the cystine-supplied cells.

\section{DISCUSSION}

The patterns of emergence of the relatively cystine-non-requiring viruses during the passages in tube cultures and the isolations of $+^{c r}$ viruses from the progeny viruses in some of the plaques formed by the $+{ }^{c r}$ viruses on cells not supplied with cystine indicate that the variant viruses were obtained through the processes of mutation and selection. The ease of obtaining relatively cystine-non-requiring mutants, of the Akron and Brooks strains especially, is emphasized by the fact that the characterization by the plaque method of the progeny in 6 plaques formed by Akron $+^{c r}$ virus and of 4 plaques formed by Brooks $+{ }^{c r}$ virus on cells not supplied with cystine revealed the presence of at least three different kinds of cystine-response mutants of Akron and at least three of Brooks. These results suggest that the formation of most of the plaques produced by Akron $+{ }^{c r}$ and Brooks $+{ }^{c r}$ on cystine-deficient cells under the conditions usually employed herein is in good part due to mutation from $+^{c r}$ to various relatively cystine-non-requiring mutants during the limited propagation of the $+^{c r}$ viruses on the plate cultures.

The isolation from a relatively clear sector of an otherwise turbid plaque formed by Akron $c r^{i}$ virus on cystine-supplied cells of a virus genetically reverted from $c r^{i}$ indicates the genetic lability of Akron $c r^{i}$ virus. It is interesting to note that the cystine-non-requiring characteristic of Akron $c r^{i}$ virus is apparently completely revertible in one mutational step. The ease of locating the mutant sectors in this system suggests that it may be useful for a study of the process of mutation in polioviruses.

The success of these passages of polioviruses on cystine-deficient monkey kidney tissue cultures in obtaining cystine-response mutants and the analogous success in obtaining cold-adapted genetic variants (Dubes \& Chapin, 1956) indicate the general usefulness of the technique of passage on cells under abnormal conditions. Thus one kind of host cell may be utilized to obtain different classes of mutant viruses simply by altering the physicochemical environment for the cell-virus system in different ways.

The de-adaptation to the original host cell system (cystine-supplied cells) shown by the Akron and Mabie $c r^{i}$ viruses is analogous to the de-adaptation to 
cells at $37^{\circ}$ shown by the cold-adapted genetic variants of Akron, Brooks and Mabie (Dubes \& Chapin, 1956; Dubes \& Wenner, 1957) and reminiscent of the classic de-adaptation to the original animal host observed in animal viruses after serial passage in a different animal host (e.g., Pasteur, Chamberland \& Roux, 1884).

The authors wish to thank Dr Herbert A. Wenner for encouragement in this work and Dr Italo Archetti and Dr Alvar A. Werder for critical reading of the manuscript. This research was aided by a grant from the National Foundation for Infantile Paralysis.

\section{REFERENCES}

Dubes, G. R. (1956a). Differences among strains of poliomyelitis viruses in plaque size on monkey kidney cells. Virology, 2, 284.

Dubes, G. R. (1956 $b$ ). Cystine requirement for normal poliovirus action on monkey kidney tissue cultures. Proc. Soc. exp. Biol., N.Y. 93, 129.

Dubes, G. R. \& Chapin, M. (1956). Cold-adapted genetic variants of polio viruses. Science, 124, 586.

Dubes, G. R. \& Chapin, M. (1957). Poliovirus mutants with altered responses to cystine (abstract). Rec. Genet. Soc. Amer. no. 26, 367.

Dubes, G. R. \& Wenner, H. A. (1957). Virulence of polioviruses in relation to variant characteristics distinguishable on cells in vitro. Virology, 4, 275.

DuLbecco, R. (1956). Quantitative aspects of virus growth in cultivated animal cells. Ciba Symp. on The Nature of Viruses, p. 147.

Dulbecco, R. \& VoGT, M. (1954). Plaque formation and isolation of pure lines with poliomyelitis viruses. J. exp. Med. 99, 167.

Dulbecco, R. \& Vogt, M. (1955). Biological properties of poliomyelitis viruses as studied by the plaque technique. Ann. N.Y. Acad. Sci. 61, 790.

Eagle, H. (1955). Nutritional needs of mammalian cells in tissue culture. Science, 122, 501.

Hanks, J. H. \& Wallace, R. E. (1949). Relation of oxygen and temperature in the preservation of tissues by refrigeration. Proc. Soc. exp. Biol., N.Y. 71, 196.

LurIA, S. E. (1953). Host-induced modifications of viruses. Cold Spr. Harb. Symp. quant. Biol. 18, 237.

Melnick, J. L. (1955). Tissue culture techniques and their application to original isolation, growth and assay of poliomyelitis and orphan viruses. Ann. N.Y. Acad. Sci. 61, 754.

Pasteur, L., Chamberland, C. \& Roux, E. (1884). Nouvelle communication sur la rage. C.R. Acad. Sci., Paris, 98, 457.

SABIN, A. B. (1956). Present status of attenuated live-virus poliomyelitis vaccine. J. Amer. med. Ass. $162,1589$.

Stanley, N. F., Dorman, D. E., Ponsford, F. \& Larkin, M. (1956). Isolation of a heat-resistant variant of poliovirus. Nature, Lond. 178, 413.

'Takemori, N., Nomura, S., Nakano, M., Morioka, Y., Henmi, M. \& Kitaoka, M. (1957). New mutation in polioviruses. Science, 125, 1195 .

Vogt, M., Dulbecco, R. \& Wennen, H. A. (1957). Mutants of poliomyelitis viruses with reduced efficiency of plating in acid medium and reduced neuropathogenicity. Virology, 4, 141.

Wenner, H. A., Miller, C. A., Kamitsuka, P. \& Wilson, J. C. (1954). Preparation and standardization of antiserums prepared with the three known types of poliomyelitis viruses. Amer. J. Hyg. 59, 221.

Younger, J. S. (1954). Monolayer tissue cultures: I. Preparation and standardization of suspensions of trypsin-dispersed monkey kidney cells. Proc. Soc. exp. Biol., N.Y. 85, 202. 

Journal of General Microbiology, Vol. 18, No. 2

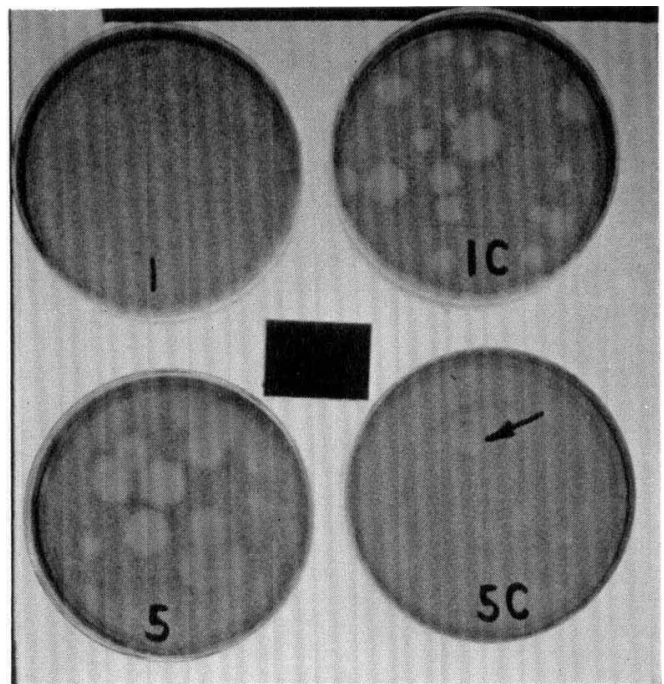

Fig. 1

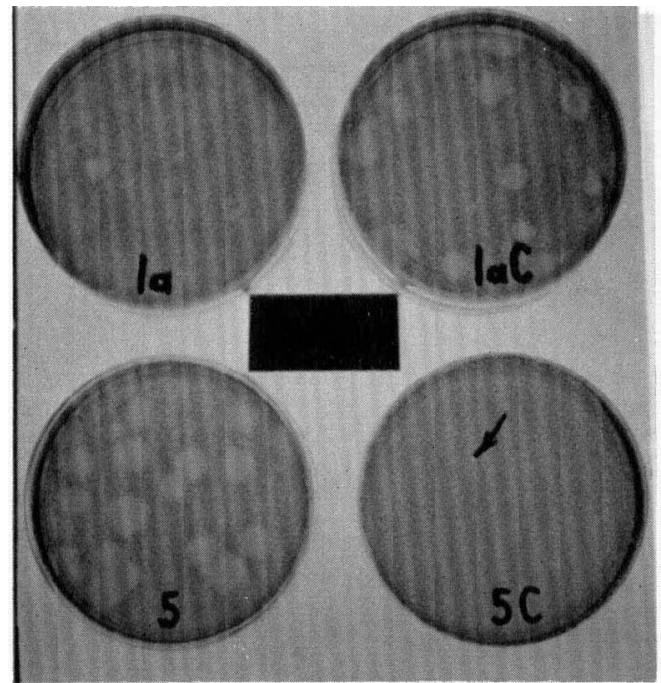

Fig. 2

G. R. Dubes and M. Chapin-Cystine-response mutants of polioviruses. Plate 1 


\section{EXPLANATION OF PLATE}

Fig. 1. A comparison of plaques formed by Akron $+{ }^{c r}$ virus (PP 1) and by Akron $c r^{i}$ virus (PP 5) on cystine-supplied monkey kidney cells and on monkey kidney cells not supplied with cystine. The plaques developed on medium D-grown cells for 4.0 days at $35.9^{\circ}$. Plates labelled 1 and $1 \mathrm{C}$ each received $0.30 \mathrm{ml}$. Akron PP 1 at $10^{-5}$ virus concentration and plates 5 and $5 \mathrm{C}$ each received $0.30 \mathrm{ml}$. Akron PP5 at $10^{-4}$ virus concentration. The maintenance medium for plates $1 \mathrm{C}$ and $5 \mathrm{C}$ was AEm with $\mathrm{L}$-cystine at $1.0 \mathrm{mM}$ for 1 and 5 was AEm without cystine. No plaques were found on plate 1. The arrow on plate $5 \mathrm{C}$ points to a turbid plaque with a diameter of $4.0 \mathrm{~mm}$. Seven turbid plaques were found on plate $5 \mathrm{C}$.

Fig. 2. A comparison of plaques formed by Mabie $+{ }^{o r}$ virus (PP 1a) and by Mabie $c r^{i}$ virus (PP 5) on cystine-supplied monkey kidney cells and on monkey kidney cells not supplied with cystine. The plaques developed on medium D-grown cells for 4.0 days at $35.9^{\circ}$. Plates labelled $1 \mathrm{a}$ and $1 \mathrm{aC}$ each received $0.30 \mathrm{ml}$. Mabie PP $1 \mathrm{a}$ at $10^{-4.4}$ virus concentration and plates 5 and $5 \mathrm{C}$ each received $0.30 \mathrm{ml}$. Mabie PP5 at $10^{-4.7}$ concentration. The maintenance medium for plates $1 \mathrm{aC}$ and $5 \mathrm{C}$ was $\mathrm{AEm}$ with L-cystine at $1.0 \mathrm{mM}$ and for $1 \mathrm{a}$ and 5 was AEm without cystine. Seven small plaques were found on plate $1 \mathrm{a}$. The rather large ill-defined lighter areas on plate $1 \mathrm{a}$ are not plaques; they are typical of cystine-deficient monolayers and may be found on control plates uninoculated with virus. Two turbid plaques were found on $5 \mathrm{C}$; one of these with a diameter of $2.5 \mathrm{~mm}$. is indicated by an arrow.

(Received 22 July 1957) 